\title{
Lipid droplet velocity is a microenvironmental sensor of aggressive tumors regulated by V-ATPase and PEDF
}

\author{
Francesca Nardi ${ }^{1} \cdot$ Philip Fitchev $^{1} \cdot$ Kyrsten M. Brooks $^{2} \cdot$ Omar E. Franco $^{1} \cdot$ Kevin Cheng $^{2} \cdot$ Simon W. Hayward $\mathbb{D}^{1} \cdot$ \\ Michael A. Welte ${ }^{3}$. Susan E. Crawford ${ }^{1,2}$
}

Received: 28 March 2019 / Revised: 4 June 2019 / Accepted: 5 June 2019 / Published online: 13 August 2019

(c) United States \& Canadian Academy of Pathology 2019

\begin{abstract}
Lipid droplets (LDs) utilize microtubules (MTs) to participate in intracellular trafficking of cargo proteins. Cancer cells accumulate LDs and acidify their tumor microenvironment (TME) by increasing the proton pump V-ATPase. However, it is not known whether these two metabolic changes are mechanistically related or influence LD movement. We postulated that LD density and velocity are progressively increased with tumor aggressiveness and are dependent on V-ATPase and the lipolysis regulator pigment epithelium-derived factor (PEDF). LD density was assessed in human prostate cancer (PCa) specimens across Gleason scores (GS) 6-8. LD distribution and velocity were analyzed in low and highly aggressive tumors using live-cell imaging and in cells exposed to low $\mathrm{pH}$ and/or treated with V-ATPase inhibitors. The MT network was disrupted and analyzed by $\alpha$-tubulin staining. LD density positively correlated with advancing GS in human tumors. Acidification promoted peripheral localization and clustering of LDs. Highly aggressive prostate, breast, and pancreatic cell lines had significantly higher maximum LD velocity (LDVmax) than less aggressive and benign cells. LDVmax was MT-dependent and suppressed by blocking V-ATPase directly or indirectly with PEDF. Upon lowering pH, LDs moved to the cell periphery and carried metalloproteinases. These results suggest that acidification of the TME can alter intracellular LD movement and augment velocity in cancer. Restoration of PEDF or blockade of V-ATPase can normalize LD distribution and decrease velocity. This study identifies V-ATPase and PEDF as new modulators of LD trafficking in the cancer microenvironment.
\end{abstract}

\section{Introduction}

Cancer cells modify their microenvironment to a lower $\mathrm{pH}$ to favor tumor progression and invasiveness [1]. This extracellular acidification is achieved via V-ATPase, a key

Supplementary information The online version of this article (https:// doi.org/10.1038/s41374-019-0296-8) contains supplementary material, which is available to authorized users.

$\triangle$ Susan E. Crawford

crawford1@uchicago.edu

1 Department of Surgery, NorthShore University Research Institute, Affiliate of University of Chicago Pritzker School of Medicine, Evanston, IL 60201, USA

2 Department of Pathology, Saint Louis University School of Medicine, 1402 South Grand Blvd., Saint Louis, MO 63104, USA

3 Department of Biology, University of Rochester, RC Box 270211, Rochester, NY 14627, USA membrane proton $\left(\mathrm{H}^{+}\right)$pump that transports $\mathrm{H}^{+}$across intracellular and plasma membranes in order to maintain a physiological intracellular $\mathrm{pH}$. The resulting acidification of organelle lumina and the extracellular space influences several biological processes, many of which are dysregulated in cancers [2, 3]. Higher V-ATPase activity has been associated with tumor aggressiveness and multidrug resistance in multiple cancers, including breast, prostate, and pancreatic cancer [4-7]. Inhibitors of V-ATPase decrease the extracellular acidification, suppress cancer cell proliferation and invasion, and prevent chemoresistance [8, 9].

Cancer cells store lipids such as triacylglycerol (TAG) and cholesterol in lipid droplets (LDs) and use them to support their proliferation and invasion. Limited studies in tumors have demonstrated that the density of LDs in cancer cells is increased and may be associated with higher aggressiveness [10-12]. In hepatocellular carcinoma, inhibition of V-ATPase was shown to interfere with cholesterol metabolism by causing cellular depletion of free cholesterol leading to a reduction in cancer cell proliferation [13]. 
Moreover, in melanoma cell lines, cholesterol depletion was found to be inhibitory to the hydrolytic and $\mathrm{H}^{+}$pumping activities of V-ATPase inducing a decrease in the migration and invasiveness capacities of these cells [14]. It is not known whether changes in the $\mathrm{pH}$ of the microenvironment or the activity of V-ATPase affect LDs.

LDs are cytoplasmic organelles consisting of a core of neutral lipids surrounded by a phospholipid monolayer with proteins either embedded in this monolayer or attached to its surface [15-18]. These organelles are found in most cells, where they play central roles in the storage and turnover of triglycerides and cholesterol esters, membrane synthesis, production of bioactive signaling molecules, and intracellular trafficking of cargo proteins. Intracellular lipid homeostasis is maintained by specific proteins, which regulate the balance between lipolysis and lipogenesis. Many of these proteins are located on the surface of LDs. One of these is pigment epithelium-derived factor (PEDF), which stimulates lipolysis and the release of free fatty acids (FFAs) [19, 20]. PEDF has also antitumor and antiangiogenic activities in cancer [21-23], and its protein levels have been found to be decreased in several tumors including those involving prostate, breast, and colon [24-26].

LDs interact with other organelles such as mitochondria, peroxisomes, and endosomes [27-30], and these interactions are dynamic [31, 32]. To accomplish various functions, LDs move along a network of microtubules (MTs) [15, 33], and several MT-associated proteins such as tubulin, dynein, and kinesin reside on the LD surface $[34,35]$; dynein and kinesins indeed promote LD movement [32-36]. In the liver, the motor protein kinesin-1 was found to regulate the secretion of triglycerides and modulate LD distribution and movement [37]. Studies in normal cells have demonstrated that LD movement within the cytoplasm can be characterized by alternating sequences of slow short-distance movement followed by fast long-distance movement. Slow LD movement is random and diffusional, whereas fast movement is directional and is driven by the molecular motors kinesin- 1 and cytoplasmic dynein that carry LDs along MTs [32]. To date, it is not known whether LD motility is different in cancer cells. There is evidence that MTs in cancer cells undergo post-translational modifications in response to cell stress [38]; however, it is not clear whether the architecture of the MT-network differs in cancer cells from that of benign cells.

We hypothesized that the increased nutrient requirements and trafficking of cargo proteins in aggressive cancer cells require more agility of LDs to move within the cellular compartment resulting in elevated LD velocity (LDV) and greater displacement when compared with lower aggressive cancer and benign cells. Using live-cell imaging, we found that when compared with lower aggressive cancer cells and benign epithelial cells, aggressive prostate, breast, and pancreatic cancer cells have significantly increased maximum LDV (LDVmax) and greater maximum displacement (Dmax), both of which were MT-dependent. Acidification of the culture medium further elevated both LDVmax and Dmax in prostate cancer (PCa) cells; this increase was V-ATPase-dependent since it was blocked by V-ATPase inhibitor Bafilomycin A1. Increased LD movement in PCa cells was inhibited by treatment with exogenous PEDF. Evaluation of the MT architecture in cancer cells revealed selective LD clustering patterns and complex MT intersections, which increase track availability. These observations suggest that high LD motility may be a feature of metabolic reprogramming in aggressive cancers and LDV acts as an intrinsic metabolic sensor in tumor cells for utilization of stored lipids to promote tumor growth, especially in a more acidic tumor microenvironment (TME).

\section{Materials and methods}

\section{Cell culture and reagents}

Cell lines were obtained from the American Type Culture Collection. Aggressive PCa cells (PC-3), breast cancer cells from metastatic (MDA-MB231) and nonmetastatic (MCF7) tumors and pancreatic cancer cells (PANC-1) were cultured at $37{ }^{\circ} \mathrm{C}$ in $5 \% \mathrm{CO}_{2}$ in DMEM/F12 medium (Thermo Fisher Scientific, Waltham, MA) supplemented with $10 \%$ fetal bovine serum (FBS; Sigma-Aldrich, Saint Louis, MO) and $1 \%$ penicillin/streptomycin. Lower aggressive PCa cells (LNCaP) were cultured at $37^{\circ} \mathrm{C}$ in $5 \% \mathrm{CO}_{2}$ in RPMI medium (Thermo Fisher Scientific, Waltham, MA) supplemented with $10 \%$ FBS and $1 \%$ penicillin/streptomycin. Benign prostate epithelial cells (NHPrE1) were used as control and were cultured in DMEM/F12 medium (Thermo Fisher Scientific, Waltham, MA) supplemented with 5\% FBS and with $1 \%$ penicillin/streptomycin, 1\% insulintransferrin-selenium-X (ITS; Gibco, Grand Island, NY), $0.4 \%$ bovine pituitary extract (BPE; Hammond Cell Tech, Windsor, CA), and $10 \mathrm{ng} / \mathrm{ml}$ epidermal growth factor (EGF; Sigma-Aldrich, St. Louis, MO) (Ming Hayward Stem cell 2010). Benign breast epithelial cells (MCF10A) were cultured in mammary epithelial cell growth medium (MEGM; Bulletkit, Lonza). After seeding overnight, cells were exposed to several different treatments: (a) $10 \mathrm{nM}$ purified PEDF protein (full-length) [39] for $24 \mathrm{~h}$; (b) $\mathrm{HCl}$ (Cat. No. SA49, Thermo Fisher Scientific, Waltham, MA) in order to acidify the medium to $\mathrm{pH}$ 6.8-6.9 with or without $1 \mathrm{nM}$ Bafilomycin A1 (Cat. No. B1793, Sigma-Aldrich, MO) for $24 \mathrm{~h}$; and (c) $5 \mu \mathrm{M}$ Nocodazole (Cat. No. M1404, SigmaAldrich, MO) for $4 \mathrm{~h}$ in order to disrupt MTs. 


\section{Immunohistochemical analyses of human PCa tissues}

The specimens available for the study $(n=128)$ consisted of benign prostate controls (normal or with benign hyperplasia), lower grade PCa with Gleason score (GS) 6 or 7, and higher grade PCa with GS 8 or 9. Immunohistochemical staining of archival paraffin embedded tissues was performed on representative histologic sections and evaluated by two pathologists. Tumor grades were confirmed. Immunohistochemical stains were performed by a previously described method used routinely in our laboratory [40]. Staining with adipose triglyceride lipase (ATGL) antibody (Cat. No. 2138, Cell Signaling Technology, Danvers, MA) was performed to identify the proteins on the LD surface. Following ATGL staining, intracytoplasmic ATGL-positive LDs were counted per cell in representative sections cut from both benign and PCa specimens at $\times 100$ objective. A minimum of 25 cells were analyzed per section. In PCa specimens, microscopic fields of highest tumor density were selected for the analysis. The tissue sections were also stained with perilipin 2 (PLIN2/ADRP) (1:50—Cat. No. sc-32448Santa Cruz Biotechnology, Dallas, TX) antibody, which showed a similar localization pattern as ATGL stained slides. The study was approved by the Institutional Review Board.

\section{Live-cell imaging and analysis}

For live-cell imaging, cells were cultured in glass-bottom dishes. Once the cells reached $\sim 50 \%$ confluence, LDs were stained for $1 \mathrm{~h}$ with $12 \mu \mathrm{g} / \mathrm{ml}$ BODIPY 493/503 (Cat. No. D3922, Thermo Fisher Scientific, Waltham, MA) added to the culture medium. Following BODIPY staining, the cells were washed three times in culture medium and subsequently treated for $24 \mathrm{~h}$ as describe above. 2D live-cell imaging was performed at $37{ }^{\circ} \mathrm{C}, 5 \% \mathrm{CO}_{2}$ in a Chamlide TC-W stage incubator system (Live Cell Instrument, Seoul, Korea) using Nikon Eclipse Ti inverted microscope equipped with Xcite 120 LED light source and Zyla sCMOS camera. Time lapse images were recorded at $180 \mathrm{~ms}$ intervals under the FITC green fluorescence channel using a $\times 60$ oil immersion objective. Cells were imaged for a minimum of $10 \mathrm{~s}$. LDs were tracked over a $10 \mathrm{~s}$ period and the maximum velocity of each LD (LDVmax) and maximum displacement (Dmax) were determined using the MTrackJ plugin in image $\mathrm{J}$. The analysis was performed using the 10 LDs with highest velocities in each cell. At least 50 LDs were used for each experimental group. We determined using 10 LDs gave consistent results after extensive pretesting using 25, 50, and 100 LDs. Adding additional LDs did not statistically alter the values obtained on a sample size of 10 LDs. For directionality of movement, the mean square displacement (MSD) for trajectories of fast moving LDs was calculated and graphed using DiPer software [41]. The movement of each LD analyzed was characterized as directional or nondirectional. Movement was considered directional when it persisted over $2 / 3$ (6.7 s) of the trajectory length as evidenced by an exponential MSD curve and the anomalous exponent $\alpha \geq 1$.1. Nondirectional movement was characterized by non-exponential curve and $\alpha<1.1$. The anomalous exponent $(\alpha)$ for a given time point was calculated using the $\log$ equation: $\log (\operatorname{MSD}(\Delta t))=\log (4 \mathrm{D})+$ $\alpha \log (\Delta t)$. The diffusion coefficient (D) was calculated from the first four time points of the MSD curve using linear regression analysis to obtain the best fit line from the formula $\operatorname{MSD}(\Delta t)=4 \mathrm{D} \Delta \mathrm{t}=\left\langle\mathrm{x}^{2}\right\rangle$, where $\Delta \mathrm{t}$ is the elapsed time, $\mathrm{D}$ is the diffusion coefficient and $\mathrm{x}^{2}$ is the slope of the best fit line.

\section{Immunofluorescence staining}

NHPrE1 and PC-3 cells were cultured on glass coverslips coated with Poly-L-Lysine (Cat. No. P4832, SigmaAldrich, MO), and once they reached $\sim 50 \%$ confluence they were fixed in $4 \%$ paraformaldehyde for $20 \mathrm{~min}$, and permeabilized with $0.1 \%$ Triton X-100 for $15 \mathrm{~min}$. Cells were first incubated for $20 \mathrm{~min}$ in 5\% normal horse serum, and then with primary and secondary antibodies for $1 \mathrm{~h}$ each. Rabbit anti- $\alpha$-tubulin (1:100-Cat. No. ab15246Abcam, Cambridge, United Kingdom), mouse anti-matrix metalloproteinase 9 (MMP-9-1:150-Cat. No. IM37100UG-EDM Millipore, Burlington, MA), and rabbit anti-total- $\beta$-catenin $(1 \mu \mathrm{g} / \mathrm{ml}$-Cat. No. ab16051-Abcam, Cambridge, United Kingdom) were used to visualized MTs and protein localization inside the cells, respectively. After staining, the coverslips were mounted on glass slides using ProLong Gold antifade reagent with DAPI (Invitrogen, Carlsbad, CA) and sealed with permaslip. Cells were then imaged using confocal microscopy (Nikon Eclipse TE 2000-U microscope equipped with NIS-Element version 4 software). To enhance the detection of the MT networks, single color images of MTs stained for $\alpha$-tubulin stain (red) were processed with Filament Sensor software v. 0.1.7, which detects and records location, orientation, length, and width for each single filament of a fluorescent image, thus allowing assessment of filament tracking [42].

\section{Western blotting}

NHPrE, LNCaP, and PC-3 cells were cultured on dishes and, once they reached $\sim 80 \%$ confluence, they were washed with PBS, scraped and lysed in M-PER + protease inhibitor buffer (Sigma, St. Louis, MO). Cell lysates were 
centrifuged at $12,000 \mathrm{rpm}$ for $20 \mathrm{~min}$ at $4{ }^{\circ} \mathrm{C}$, and then the protein concentration was determined using the Pierce $660 \mathrm{~nm}$ Protein Assay Reagent (Thermo Fisher Scientific, Waltham, MA) and compared to a standard. Proteins separated by precast gels (Mini-PROTEAN TGX Stain-Free Gel-Bio-Rad, Des Plaines, IL) were transferred onto 0.2 um polyvinylidene difluoride (PVDF) membranes (BioRad, Des Plaines, IL), blocked in 5\% bovine serum albumin in PBS-T, and incubated with primary and secondary antibodies. PEDF (1:1000-Cat. No. AB-PEDF4-BioProducts MD, Middletown, MD), total- $\beta$-catenin $(1 \mu \mathrm{g} / \mathrm{ml}-$ Cat. No. ab16051-Abcam, Cambridge, United Kingdom), kinesin 5B $(0.5 \mu \mathrm{g} / \mathrm{ml}$-Cat. No. ab5629-Abcam, Cambridge, United Kingdom), and V-ATPase (ATP6V1E11:200-Cat. No. HPA003156-Sigma-Aldrich, MO) antibodies were used. GAPDH (1:1000—Cat. No. 2118-Cell Signaling Technology, Danvers, MA) antibody was used as normalizer. The membrane was then incubated at room temperature with enhanced chemiluminescence detection reagents (Bio-Rad, Des Plaines, IL), and the bands were visualized by chemiluminescence using the ChemiDoc Touch Imaging System (Bio-Rad, Des Plaines, IL).

\section{Statistical analysis}

Statistical analysis was performed using Student's $t$-test, where the differences were considered statistically significant when $P<0.05$. This analysis was performed using GraphPad Prism, version 7.03. ImageJ software was used to analyze MT length and to quantify the protein levels by densitometry.

\section{Results}

\section{Increased LD density correlates with advancing grades of human PCa tumors and cell lines}

To determine whether the increase in intracellular LD density correlated with the aggressiveness of cancer cell lines, we analyzed the number of LDs by BODIPY staining (green) in PCa cells, LNCaP, and PC-3, and in benign prostate epithelial cells (NHPrE1) (Fig. 1a). The number of LDs was significantly increased in more aggressive androgen-independent PC-3 cells when compared with less
A
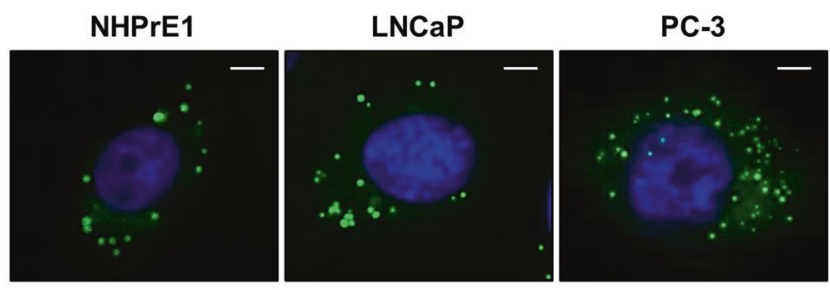

D

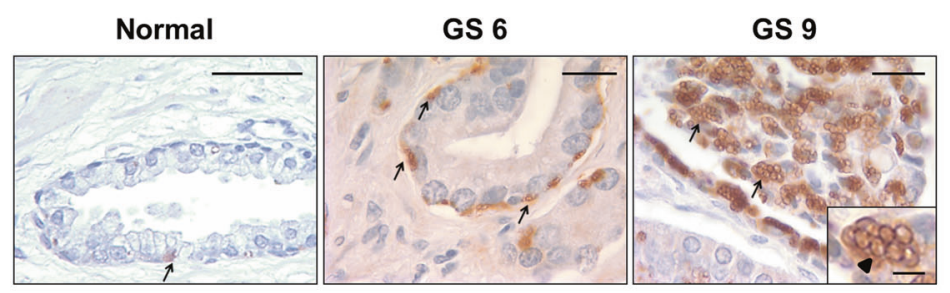

B

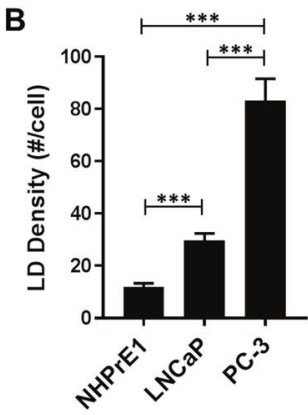

E

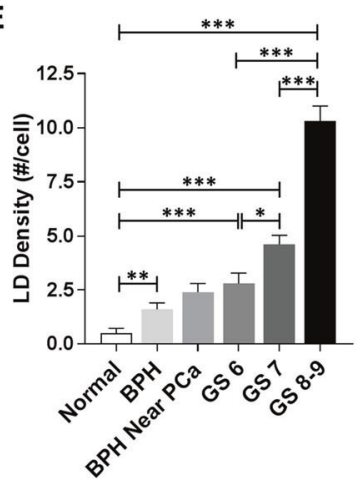

C

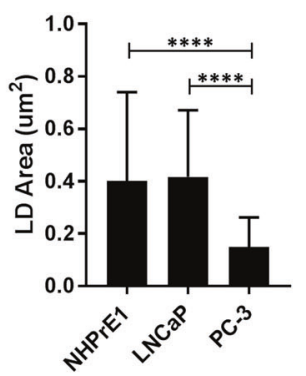

$\mathbf{F}$

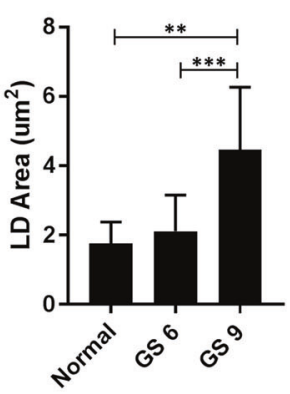

Fig. 1 LD density in prostate benign epithelial, low-aggressive and highly aggressive cancer cells. a Lipid droplets (LDs) were stained with BODIPY (green staining) in cultured benign prostate epithelial cells (NHPrE1), lower aggressive prostate cancer (PCa) LNCaP cells, and higher aggressive PCa PC-3 cells. Scale bars: $10 \mu \mathrm{m}$. b The total number of LDs was counted per single cell. $n=50$. $\mathbf{c}$ LD size defined by their cross-sectional area was calculated in NHPrE1, LNCaP, and PC-3 cells. $n=50$. d Human normal prostate, lower, and higher grade PCa with Gleason Score 6 (GS 6) and 9 (GS 9) tissues were stained for adipose triglyceride lipase (ATGL)-positive LDs (arrows and arrowhead, brown staining). Scale bars: $20 \mu \mathrm{m}$. Scale bar insert: $5 \mu \mathrm{m}$. e The ATGL-positive LD density was assessed in normal prostate epithelium, benign prostate hyperplasia (BPH), GS 6, GS 7, and GS 8-9 prostate cancer $(\mathrm{PCa})$ tissues. $n=128$. $\mathbf{f}$ The cross-sectional area of LDs was calculated in normal epithelial cells, GS 6, and GS $9 \mathrm{PCa}$ tissues. Values are mean \pm SEM. Student's unpaired $t$-test. ${ }^{*} P<0.05$, $* * P<0.01, * * * P<0.001$ 
aggressive androgen-dependent LNCaP (PC-3 vs LNCaP: $83.14 \pm 8.41$ vs $29.75 \pm 2.60 ; P<0.001)$ and benign prostate epithelial cells (PC-3 vs NHPrE1: $83.14 \pm 8.41$ vs $11.92 \pm 1.34 ; P<0.001)$. LNCaP cells showed a higher mean LD density when compared with normal cells (LNCaP vs NHPrE1: $29.75 \pm 2.60$ vs $11.92 \pm 1.34 ; P<$ 0.001) (Fig. 1b). Since LD size is important for cargo proteins and signaling, differences in the cross-sectional area of LDs were evaluated within our cell types. NHPrE1 had a mean LD area of $0.40 \pm 0.3 \mu \mathrm{m}^{2}$, which was similar to the one observed for LNCaP cells $\left(0.42 \pm 0.3 \mu \mathrm{m}^{2}\right)$. In contrast, in more aggressive PC-3 cells, the mean LD area was significantly decreased when compared with both NHPrE1 (PC-3 vs NHPrE1: $0.15 \pm 0.01$ vs $0.40 \pm 0.05$; $P<$ 0.0001 ) and less aggressive LNCaP cells (PC-3 vs LNCaP: $0.15 \pm 0.01$ vs $0.42 \pm 0.03 ; P<0.0001$ ) (Fig. 1c). To test if LD density in PCa positively correlated with tumor grade or GS, we assessed LD density in formalin fixed paraffinembedded human prostate benign and cancer tissues (Fig. 1d). Because lipids are extracted from the sample during tissue processing, direct detection of neutral lipids (with dyes such as Oil-Red-O or BODIPY) in paraffinembedded tissues is not possible or consistent. For this reason, the tissue samples were stained by immunohistochemistry for ATGL, a LD associated protein that resides on the LD surface [43]. The density of ATGL-positive LDs increased progressively with disease grade. Higher grade human PCa with GS 8-9 were characterized by a significantly higher LD density when compared with lower grade GS 7 (GS 8-9 vs GS 7: $10.30 \pm 0.70$ vs $4.60 \pm 0.43$; $P<0.001$ ), GS 6 PCa (GS $8-9$ vs GS $6: 10.30 \pm 0.70$ vs $2.80 \pm 0.49 ; P<0.001$ ), and normal prostate epithelial cells (GS 8-9 vs Normal: $10.30 \pm 0.70$ vs $0.50 \pm 0.22 ; P<0.001$ ) (Fig. 1e). Also GS 6 and GS $7 \mathrm{PCa}$ as well as benign prostatic hyperplasia (BPH) showed a significant increase in the number of intracellular LDs when compared with normal prostate epithelial cells (GS 6 vs Normal: $2.80 \pm 0.49$ vs $0.50 \pm 0.22 ; P<0.001$; GS 7 vs Normal: $4.60 \pm 0.43$ vs $0.50 \pm 0.22 ; P<0.001 ; B P H$ vs Normal: $1.60 \pm 0.31$ vs $0.50 \pm 0.22 ; P<0.01)$. LD density increased in a stepwise fashion when comparing $\mathrm{BPH}$ to $\mathrm{BPH}$ near cancer and to GS $6 \mathrm{PCa}$, although the value did not reach statistical significance (Fig. 1e). Moreover, higher grade human PCa with GS 9 had larger LDs in terms of area when compared with lower grade GS 6 (GS 9 vs GS 6: $4.47 \pm 0.32$ vs $2.12 \pm$ $0.23 ; P<0.001)$ and normal prostate epithelial cells (GS 9 vs Normal: $4.47 \pm 0.32$ vs $1.76 \pm 0.28 ; P<0.01$ ) (Fig. 1f). A stepwise increase of lipid content with tumor aggressiveness was confirmed by perilipin 2 (PLIN2), which is an alternative marker for intracellular LD staining (see supplemental data, Fig. S1). These data suggest that accumulation of intracellular lipids is progressive as a tumor advances to a higher grade, thus, expanding the resident source of nutrients to keep pace with the metabolic needs of an aggressive tumor in the TME.

\section{Directional movement and maximum LDV are increased in aggressive cancer cells}

To investigate whether LD movement correlates with tumor aggressiveness across various cell lineages, we performed live-cell imaging of LDs stained with BODIPY (green) and calculated the LDV in prostate, breast and pancreatic cancer cell lines and compared them to benign cells (Fig. 2a). Tracking the movement of single LDs demonstrated a significantly higher maximum LD velocity (LDVmax) in more aggressive $\mathrm{PCa}$ cells, PC-3, compared with less aggressive PCa cells, $\mathrm{LNCaP}$ (PC-3 vs LNCaP: $1.43 \pm 0.13$ vs $1.01 \pm$ $0.08 \mu \mathrm{m} / \mathrm{s} ; P<0.01$ ), and NHPrE1 cells (PC-3 vs NHPrE1: $1.43 \pm 0.13$ vs $0.48 \pm 0.05 \mu \mathrm{m} / \mathrm{s} ; P<0.001)$. Low-aggressive $\mathrm{PCa}$ cells, LNCaP, still showed a significantly higher LDVmax when compared with benign cells (LNCaP vs NHPrE1: $\quad 1.01 \pm 0.08$ vs $\quad 0.48 \pm 0.05 \mu \mathrm{m} / \mathrm{s} ; \quad P<0.001)$ (Fig. 2a). The maximum velocities of individual LDs reached $3.4 \mu \mathrm{m} / \mathrm{s}$ in PC-3 cells, $2.9 \mu \mathrm{m} / \mathrm{s}$ in LNCaP cells, and $1.5 \mu \mathrm{m} / \mathrm{s}$ in benign cells. To investigate whether high LDV may be a more universal metabolic adaptation of other aggressive tumor cell types, we also analyzed LDV in breast benign epithelial cells (MCF10A), nonmetastatic (MCF-7), and metastatic (MDA-MB231, referred to as MDA) cancer cells (see supplemental movies) and in pancreatic (PANC1) cancer cells (Fig. 2a). Similar to high-grade PCa cells, metastatic breast cancer cells displayed significantly higher LDVmax compared with nonmetastatic breast cancer cells (MDA vs MCF-7: $1.66 \pm 0.08$ vs $0.91 \pm 0.07 \mu \mathrm{m} / \mathrm{s}$; $P<0.001$ ) and benign breast epithelial cells (MDA vs MCF10A: $\quad 1.66 \pm 0.08$ vs $0.91 \pm 0.07 \mu \mathrm{m} / \mathrm{s} ; \quad P<0.001)$ (Fig. 2a). LDVmax in PANC-1 was found to be comparable to the level of other metastatic cells. Most notably, all three aggressive cancer cells (PC-3, MDA, and PANC-1) were characterized by high LDVmax values, which did not differ significantly despite the fact that tumors arose from three different organs, namely prostate, breast, and pancreas. We speculate that there may be a common upper velocity threshold in high-grade tumors for intracellular movement of LDs.

Since the LDV range was similar in all aggressive tumors tested, we focused all of our further analyses on PCa and considered the data to be a potential prototype for other cancer cell types regarding LDV and MT morphology. To assess whether high LDV max is associated with a longer displacement of LDs from their original position, the maximum displacement (Dmax) of fast-moving LDs was calculated over $10 \mathrm{~s}$ periods. We observed that Dmax in aggressive PC-3 cells was significantly higher compared with both low-aggressive PCa (PC-3 vs LNCaP: $1.10 \pm 0.11$ 
Fig. 2 LDVmax and Dmax are increased in aggressive cancer cells and they depend on an intact MT-network. LDs were stained with BODIPY and a their maximum velocity (LDVmax) was calculated in NHPrE1, LNCaP, and PC-3 cells, breast benign epithelial cells (MCF10A), nonmetastatic (MCF-7) and metastatic (MDA) cancer cells, and in pancreatic (PANC-1) cancer cells. b The maximum displacement (Dmax), defined by the longest vector of displacement from the point of origin in a track, was assessed in NHPrE1, LNCaP and PC-3 cells. $\mathbf{c}$ The proportion of directional movement was evaluated in benign and $\mathrm{PCa}$ cells. d Nondirectional movement of an LD in a PCa cell as indicated by the nonlinear trajectory (black arrow: starting point; red arrow: ending point). e Directional movement of an LD in a PCa cell up to for $\sim 2 / 3$ of its length (asterisk) as represented by the linear trajectory (black arrow: starting point; red arrow: ending point). $\mathbf{f}$ Nondirectional movement was assessed using a non-quadratic mean square displacement (MSD) plot. g Directional movement was assessed using a quadratic MSD. $n=50$. Values are mean \pm SEM. Student's unpaired $t$-test. $* * P<0.01$, $* * * P<0.001$
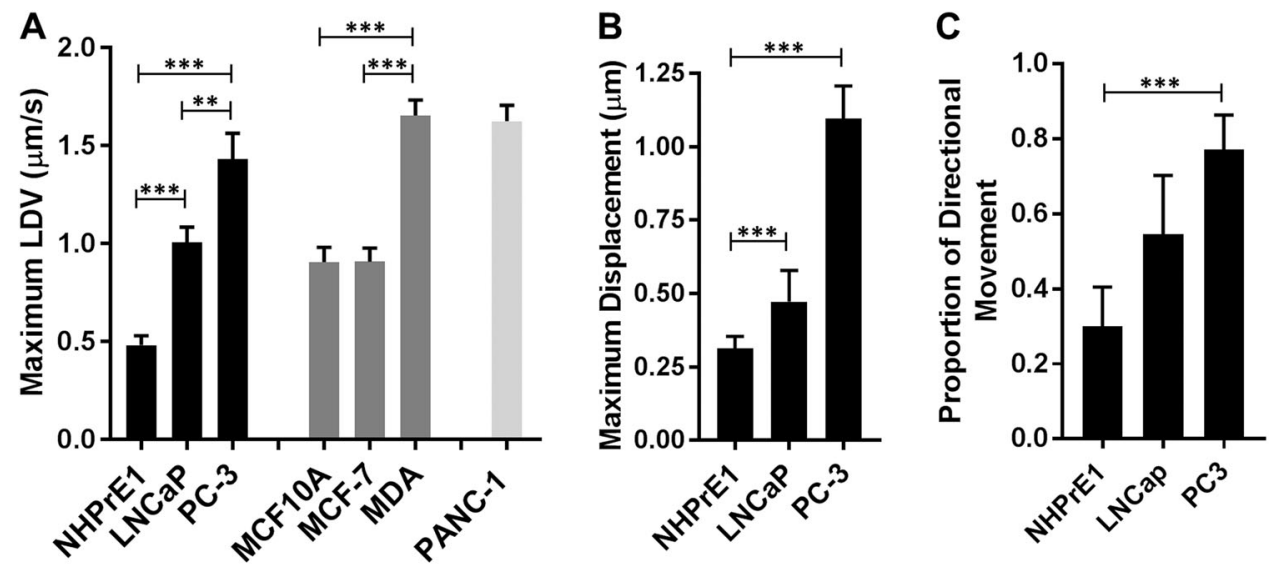

D
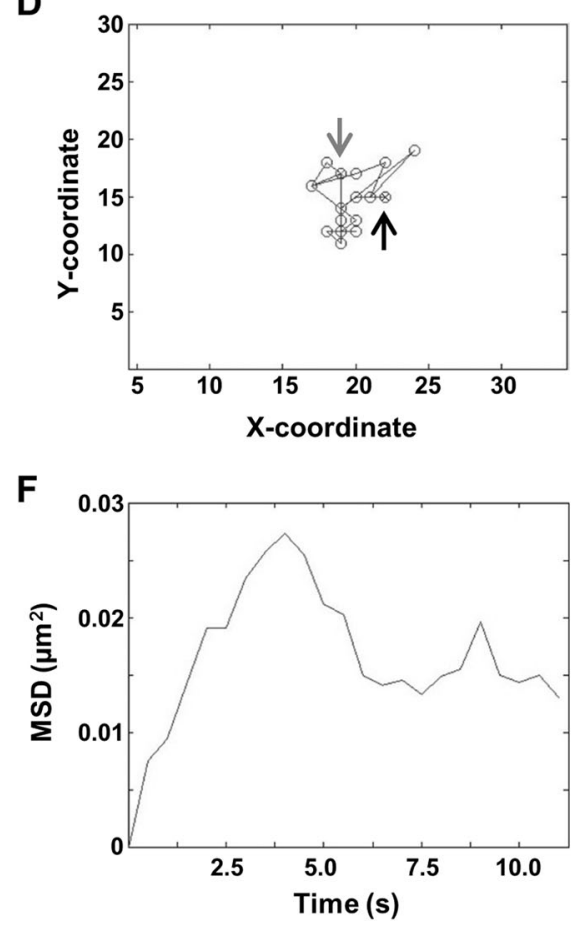

E

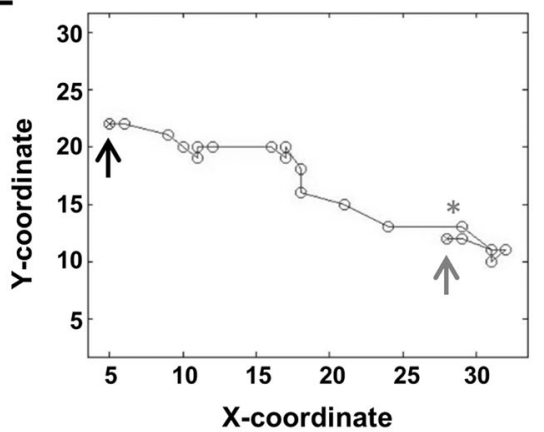

G

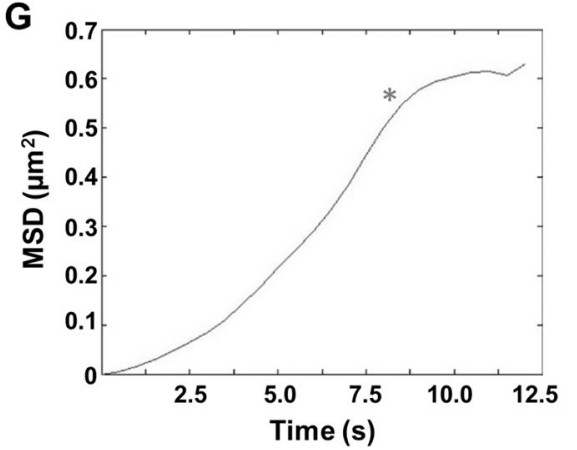

vs $0.47 \pm 0.11 \mu \mathrm{m} ; P<0.001)$ and normal epithelial cells (PC-3 vs NHPrE1: $1.10 \pm 0.11$ vs $0.31 \pm 0.04 \mu \mathrm{m} ; P<$ 0.001) (Fig. 2b). To evaluate the directionality of LD movement, the MSD was calculated. In PCa cells, LDs demonstrated both nondirectional movement with a nonlinear trajectory (Fig. 2d) and directional movement with a more linear trajectory (Fig. 2e). Nondirectionally moving LDs were characterized using a non-quadratic MSD plot (Fig. 2f), whereas those moving directionally displayed a quadratic MSD (Fig. 2g). In all experiments, aggressive PC3 cells had a significantly higher proportion of directional movement compared with normal prostate epithelial cells (PC-3 vs NHPrE1: $0.77 \pm 0.09$ vs $0.30 \pm 0.11 ; P<0.01$ ). Similar results were found in low-aggressive LNCaP cells, where a higher proportion of directional movement was evident when compared with normal prostate epithelium, although the increase did not achieve statistical significance (Fig. 2c).

\section{PEDF suppresses LDVmax in PCa cells}

PEDF is a multifunctional protein known for its antitumor and antiangiogenic functions [21, 40]. While normal cells express abundant levels of PEDF, aggressive tumors typically show a decrease in PEDF protein [44-46]. To assess the expression levels of PEDF protein in PCa cells, western blot analysis was performed (Fig. 3a). Compared with benign cells, the levels of PEDF were significantly decreased in both LNCaP (LNCaP vs NHPrE1: 65.90 \pm 1.40 vs $121.70 \pm 1.65 ; P<0.01)$ and PC-3 cells (PC-3 vs NHPrE1: $\quad 64.10 \pm 1.90$ vs $121.70 \pm 1.65 ; \quad P<0.01)$ (Fig. 3a). 
Fig. 3 PEDF suppresses LDVmax in prostate cancer cells. a PEDF (50 kD) levels were analyzed by western blot in NHPrE1, LNCaP, and PC-3 cells and normalized by GAPDH (37 kD). NHPrE1, LNCaP, and PC-3 cells were treated with $10 \mathrm{nM}$ purified PEDF protein for $24 \mathrm{~h}$ and $\mathbf{b}$ LDVmax and c Dmax were measured and compared with the untreated cells (CTR). d The total number of LDs was counted per single cell in NHPrE1, LNCaP and PC-3 cell lines with or without PEDF treatment. $n=50$. Values are mean \pm SEM. Student's unpaired t-test. $* P<0.05, * * P<$ $0.01, * * * P<0.001, * * * * P<$ 0.0001
A
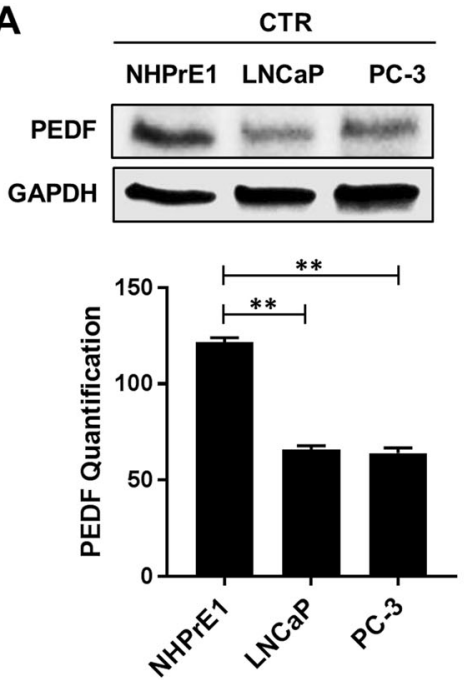

C

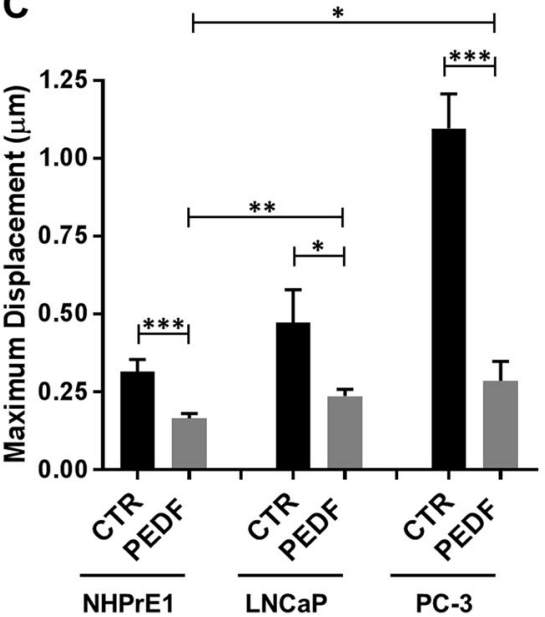

B

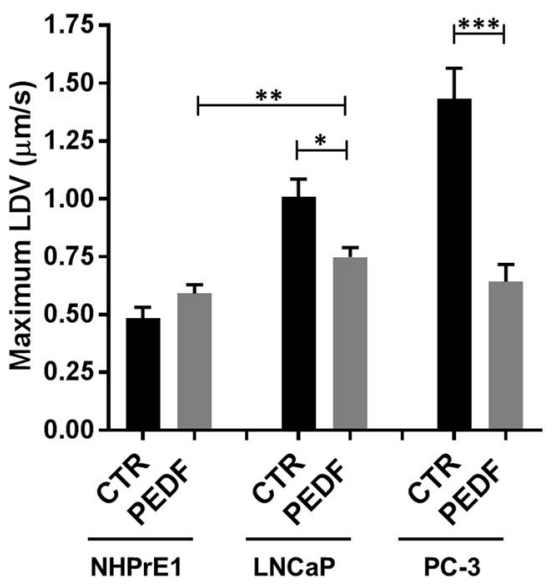

D

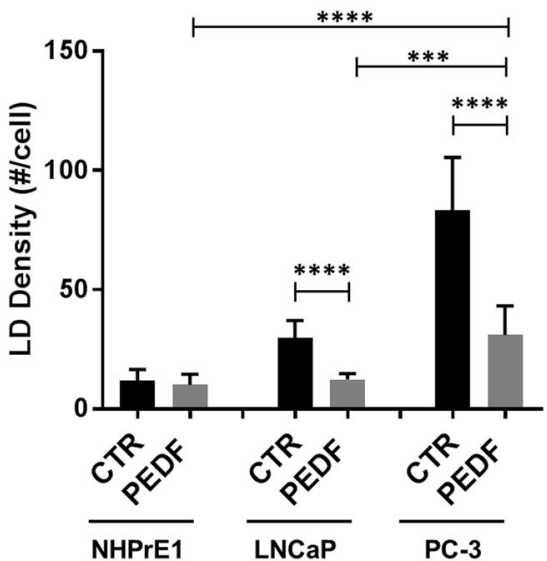

We investigated whether restoration of PEDF using recombinant full-length protein would alter LDV in $\mathrm{PCa}$ cells. Addition of PEDF resulted in reduction of LDVmax in both more aggressive and less aggressive $\mathrm{PCa}$ cells (Fig. 3b). In particular, it decreased LDVmax by 55\% in PC-3 cells (PC-3 PEDF vs PC-3 CTR: $0.64 \pm 0.07$ vs $1.43 \pm 0.13 \mu \mathrm{m} / \mathrm{s} ; \quad P<0.001)$ and $26 \%$ in $\mathrm{LNCaP}$ cells (LNCaP PEDF vs LNCaP CTR: $0.75 \pm 0.04$ vs $1.01 \pm 0.08$ $\mu \mathrm{m} / \mathrm{s} ; P<0.05)$ when compared with the untreated controls (Fig. 3b). Following PEDF treatment, the reduced LDVmax did not differ significantly between the two PCa cell lines, LNCaP and PC-3. The treatment with exogenous PEDF also significantly reduced Dmax in both benign and cancer cell lines, with the highest reduction in displacement by $74 \%$ in PC-3 cells (PC-3 PEDF vs PC-3 CTR: $0.29 \pm 0.06$ vs $1.10 \pm 0.11 \mu \mathrm{m} ; P<0.001), 49 \%$ in $\mathrm{LNCaP}$ cells $(\mathrm{LNCaP}$ PEDF vs LNCaP CTR: $0.24 \pm 0.02$ vs $0.47 \pm 0.11 \mu \mathrm{m} ; P<$ 0.05 ), and $45 \%$ in NHPrE1 cells (NHPrE1 PEDF vs NHPrE1 CTR: $0.17 \pm 0.02$ vs $0.31 \pm 0.04 \mu \mathrm{m} ; P<0.001$ ) when compared with the untreated cells (Fig. 3c). In the PEDF treated groups, both LNCaP and PC-3 showed an increase in displacement when compared with the normal prostate epithelium (LNCaP PEDF vs NHPrE1 PEDF: $0.24 \pm 0.02$ vs $0.17 \pm 0.02 \mu \mathrm{m} ; P<0.01$; PC-3 PEDF vs NHPrE1 PEDF: $0.29 \pm 0.06$ vs $0.17 \pm 0.02 ; P<0.05$ ); however, there was no significant difference between the two PCa lines (Fig. 3c). In addition, restoration of PEDF also reduced the intracellular LD number in both PCa cells, LNCaP (LNCaP PEDF vs LNCaP CTR: $12.25 \pm 0.90$ vs $29.75 \pm 2.60 ; P<0.0001)$ and PC-3 (PC-3 PEDF vs PC-3 CTR: $31.00 \pm 3.54$ vs $83.14 \pm 8.41 ; P<0.0001)$ when compared with the baseline (Fig. 3d). Following PEDF treatment, aggressive PC-3 cells continued to demonstrate a higher number of LDs when compared with less aggressive LNCaP cells (PC-3 PEDF vs LNCaP PEDF: $31.00 \pm 3.54$ vs $12.25 \pm 0.90 ; P<0.001)$ or normal prostate epithelium (PC3 PEDF vs NHPrE1 PEDF: $31.00 \pm 3.54$ vs $10.15 \pm 1.22$; $P<0.0001$ ) (Fig. 3d). 


\section{A more acidic TME increases LDVmax and promotes LD peripheral clustering in an V-ATPase-dependent manner}

Acidification of the TME is one mechanism used by tumor cells to facilitate invasion and progression [47]. This extracellular acidification is achieved via V-ATPase, a key proton $\left(\mathrm{H}^{+}\right)$pump located within membranes, which transports $\mathrm{H}^{+}$in order to maintain a physiological intracellular $\mathrm{pH}$. By western blot, we saw that the protein levels of V-ATPase (ATP6V1E1) were increased in aggressive PC-3 cells compared with $\mathrm{LNCaP}$ (PC-3 vs LNCaP: $189.90 \pm 0.65$ vs $89.35 \pm 0.35 ; P<0.0001)$ and normal cells (PC-3 vs NHPrE1: $189.90 \pm 0.65$ vs $55.50 \pm$ $0.50 ; P<0.0001$ ) (Fig. 4a). To investigate whether more acidic conditions promote an increase in LDV, we analyzed LDVmax in live cells at $\mathrm{pH}$ 6.8-6.9. This $\mathrm{pH}$ level allowed cell viability to be maintained, thus, reducing the likelihood of additional variables associated with cell death. Although there was no effect on LDVmax in
A

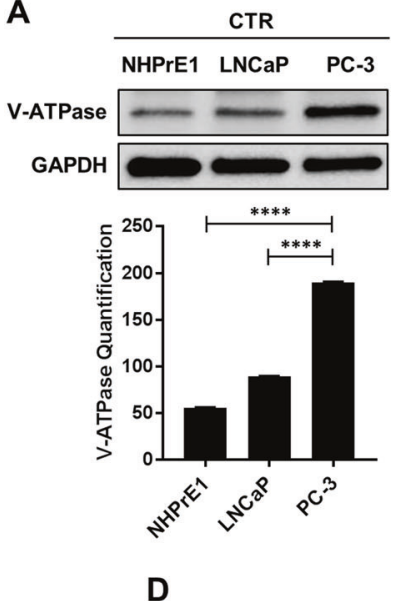

D

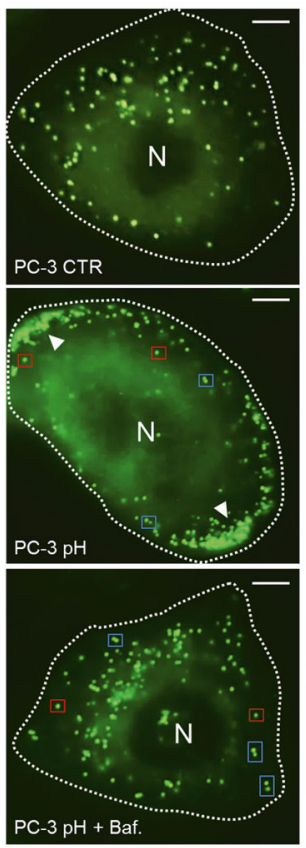

B

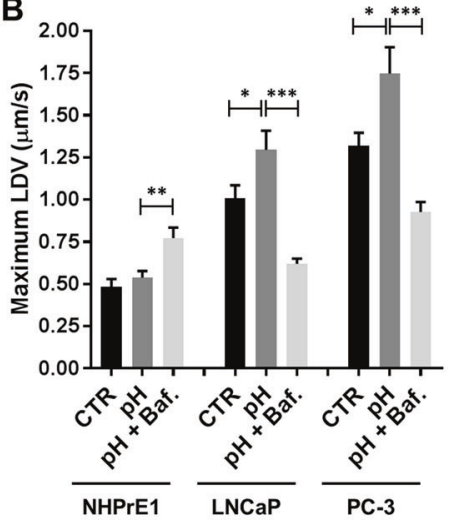

E

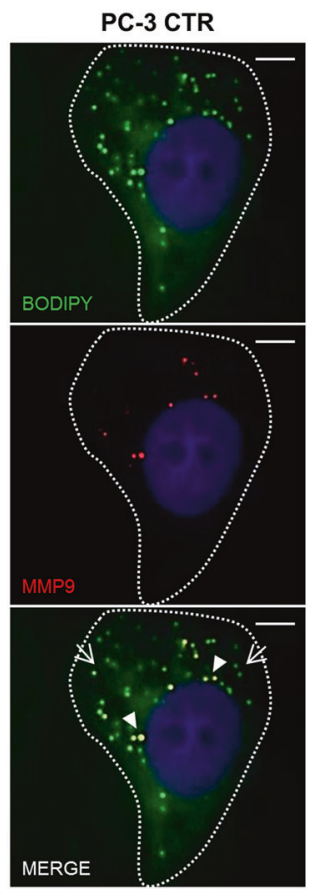

C
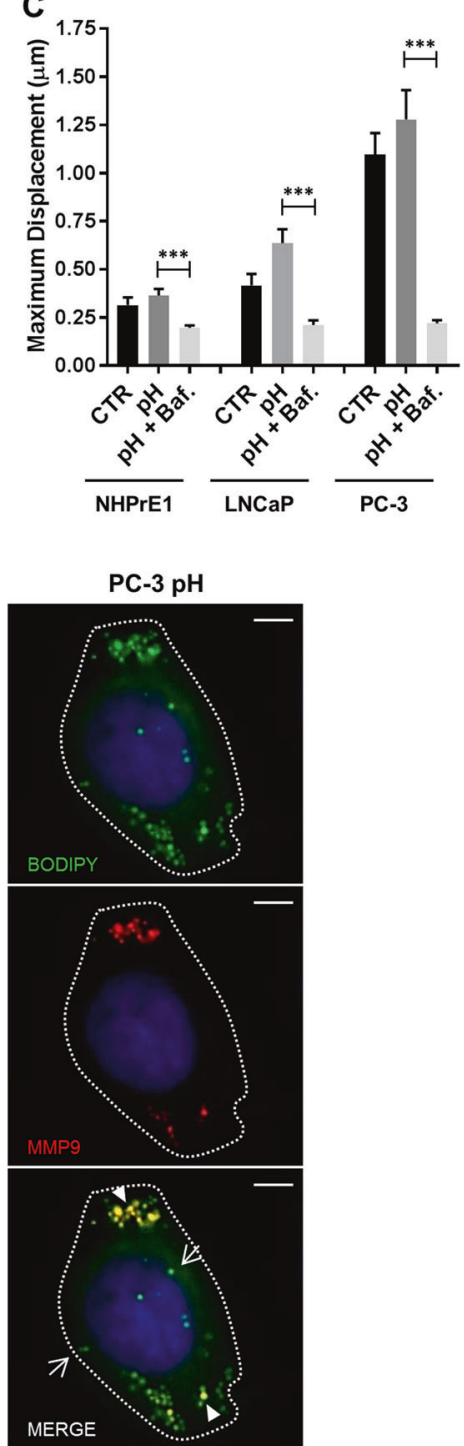

Fig. 4 LD movement and localization are dependent on V-ATPase in prostate cancer cells. a V-ATPase (ATP6V1E1) $(26 \mathrm{kD})$ levels were analyzed by western blot in NHPrE1, LNCaP, and PC-3 cells and normalized by GAPDH $(37 \mathrm{kD})$. NHPrE1, LNCaP and PC-3 cells were treated with $7.1 \mathrm{nM} \mathrm{HCl}$ with or without $1 \mathrm{nM}$ Bafilomycin A1 (Baf.) and b LDVmax and $\mathbf{c}$ Dmax were measured and compared with the controls (CTR). d LDs were stained with BODIPY (green) in PC-3 cells control and treated with $7.1 \mathrm{nM} \mathrm{HCl}$ with or without $1 \mathrm{nM}$ Bafilomycin A1 (PC-3 pH and PC-3 pH + Baf. A1) in order to analyze their intracellular localization (arrowhaeds: LD clusters; red boxes: single LDs; blue box: double LDs). Scale bars: $10 \mu \mathrm{m}$. e PC-3 cells control (PC-3 CTR) and treated with $7.1 \mathrm{nM} \mathrm{HCl}(\mathrm{PC}-3 \mathrm{pH})$ were stained with anti-MMP-9 antibody (red) and BODIPY (green) in order to visualize the intracellular localization of MMP-9 protein and LDs (arrow: LD without MMP-9; arrowheads: co-localization between LD and MMP-9). Scale bars: $10 \mu \mathrm{m} . n=50$. Values are mean \pm SEM. Student's unpaired $t$-test. $* P<0.05, \quad * * P<0.01, \quad * * * P<0.001$, $* * * * P<0.0001$ 
normal prostate epithelium cells subjected to lower $\mathrm{pH}$, blockade of V-ATPase by Bafilomycin A1 (Baf.) did result in an increase in LDVmax by $29.9 \%$ when compared with the acidified medium alone (NHPrE1 $\mathrm{pH}+$ Baf. vs NHPrE1 pH: $0.77 \pm 0.06$ vs $0.54 \pm 0.04 ; P<0.01$ ) (Fig. 4b). Unlike normal cells, PCa cells subjected to lower $\mathrm{pH}$ had significant elevations in LDVmax by $27.3 \%$ in $\mathrm{LNCaP}$ and $21.9 \%$ in PC-3 cells when compared with the baselines (LNCaP pH vs LNCaP CTR: $1.30 \pm 0.11$ vs $1.01 \pm 0.08 ; P<0.05 ;$ PC- 3 pH vs PC-3 CTR: $1.75 \pm 0.16$ vs $1.32 \pm 0.08 ; P<0.05)$. Inhibition of V-ATPase in both cancer cell lines caused a significant decrease in LDVmax when compared with the acidified cells $(\mathrm{LNCaP} \mathrm{pH}+$ Baf. vs LNCaP pH: $0.62 \pm 0.03$ vs $1.30 \pm 0.11 ; P<0.001$; PC-3 pH + Baf. vs PC-3 pH: $0.93 \pm 0.06$ vs $1.75 \pm 0.16$; $P<0.001$ ) (Fig. $4 \mathrm{~b}$ ). To determine if maximum displacement (Dmax) of LDs was influenced by $\mathrm{pH}$, cells were exposed to lower $\mathrm{pH}$ conditions (pH 6.8-6.9) (Fig. 4c). All three cell lines, NHPrE1, LNCaP, and PC-3, demonstrated a statistically significant decrease in LD maximum displacement when V-ATPase was blocked with Bafilomycin A1 (NHPrE1 pH + Baf. vs NHPrE1 pH: $0.20 \pm 0.01$ vs $0.36 \pm 0.03 ; P<0.001 ; \mathrm{LNCaP} \mathrm{pH}+\mathrm{Baf}$. vs $\mathrm{LNCaP} \mathrm{pH}$ : $0.21 \pm 0.03$ vs $0.64 \pm 0.07 ; P<0.001 ; \mathrm{PC}-3 \mathrm{pH}+$ Baf. vs PC-3 pH: $0.22 \pm 0.02$ vs $1.28 \pm 0.15 ; P<0.001$ ) (Fig. $4 \mathrm{c}$ ).

LD trafficking within cells has the potential to promote dynamic interactions with other organelles and has been implicated in lipid transfer [36]. The environmental mechanisms controlling LD movement are not well understood. To determine whether lowering $\mathrm{pH}$ can affect $\mathrm{LD}$ intracellular localization, the organelles were stained with BODIPY (green) and assessed under live-cell imaging. At pH 6.8-6.9, LDs in PC-3 cells were observed to form clusters and marginalized along the edges of cells (Fig. 4d, central panel), a site that could facilitate migration and invasion. To test if V-ATPase regulated this LD phenotype, the cells were treated with a V-ATPase inhibitor (Fig. 4d, lower panel). Interestingly, the LDs moved away from the edge of the cell as in the baseline condition. Single LDs (Fig. 4d, red boxes) often paired with another LD forming doublets (Fig. 4d, blue boxes), and the movement changed from directional to a "to and fro" pattern. At a lower $\mathrm{pH}$ conditions, $\sim 40 \%$ of LDs co-localized with matrix metalloproteinase 9 (MMP-9), which is an enzyme involved in the degradation of extracellular matrix, thus, facilitating cell migration and invasion (Fig. 4e). This co-localization was significantly higher when compared with the baseline conditions where nearly $20 \%$ of LDs showed MMP-9 on their surface. Interestingly, not only the number of LDs colocalizing with MMP-9, but also the intracellular localization of MMP-9 was different between lower $\mathrm{pH}$ and control PC-3 cells. In fact, while at the baseline condition MMP-9LDs were diffuse throughout the cytoplasm with most of them in the perinuclear region of the cell, at lower $\mathrm{pH}$ conditions the majority of MMP-9-LDs were located in the peripheral region of the cell close to the edge suggesting their potential role in facilitating cancer cell migration and invasion (Fig. 4e). This localization pattern was unique to MMP-9 since MMP-2 remained diffusely located in the cytoplasm even after a change in $\mathrm{pH}$.

Higher levels of V-ATPase have been shown to activate the Wnt/ $\beta$-catenin signaling pathway [48, 49]. This pathway has been implicated in many activities including regulation of MTs by PEDF, which can act as a Wnt inhibitor by decreasing $\beta$-catenin [50]. We tested whether the Wnt pathway was activated in the most aggressive cells, PC-3, with the highest LDVmax. When compared with LNCaP and normal epithelial cells, PC-3 cells showed a significant increase in total $\beta$-catenin (PC-3 vs LNCaP: $108.40 \pm 1.85$ vs $14.50 \pm 2.30 ; P<0.001 ;$ PC- 3 vs NHPrE1: $108.4 \pm 1.9$ vs $54.15 \pm 2.15 ; P<0.01$ ) (see supplemental data, Fig. S2A). Immunofluorescence was performed to identify the intracellular localization of active $\beta$-catenin in PC- 3 cells versus benign cells (see supplemental data, Fig. S2B). While in NHPrE1 cells $\beta$-catenin was minimally expressed and localized mainly in the cytoplasm, in PC-3 cells the protein was highly expressed and was located in both the cytoplasm and the nucleus. The presence of active nuclear $\beta$-catenin was confirmed using z-stack analysis and by performing vertical cuts through the nucleus (Fig. S2B).

\section{MT architecture of cancer cells reveals longer MTs with directionality}

Given that LDs in cancer cells exhibited more displacement than in normal cells, we used a MT filament analyzer to reconstruct the directionality and length of the MTs. The normal prostate epithelial cells had shorter MTs organized in various planes (denoted by a range of different colors), whereas cancer cells showed a more dominant directional pattern (denoted by narrower range of colors in red-orange colorway) (Fig. 5a). To assess whether increased MT length was a consistent feature of cancer cells compared with normal epithelial cells, we measured MTs. We observed that in PCa cells the MTs were significantly longer when compared with normal cells (PC-3 vs NHPrE1: $8.22 \pm 0.73$ vs $2.72 \pm 0.21 \mu \mathrm{m} ; P<0.0001$ ) (Fig. 5b).

To assess whether increased LD movement in aggressive cancer cells was dependent on the integrity of MTs, PC-3 cells were treated with $5 \mu \mathrm{M}$ Nocodazole (Noco) in order to disrupt MTs. Aggressive PCa PC-3 cells treated with Nocodazole showed a $26 \%$ decrease in LDVmax when compared with PC-3 control (PC-3 Noco vs PC-3 C: $1.09 \pm$ 0.05 vs $1.47 \pm 0.12 \mu \mathrm{m} / \mathrm{s} ; P<0.05$ ) (Fig. 5c). The same treatment decreased also Dmax by $81.2 \%$ when compared with the baseline (PC-3 Noco vs PC-3 C: $0.20 \pm 0.01$ vs 
A

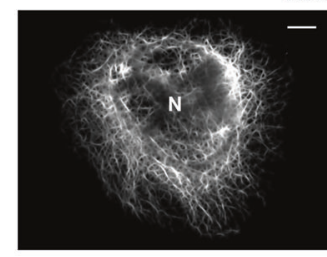

B

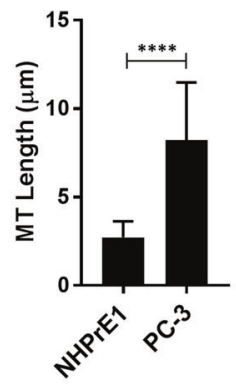

C
NHPrE1
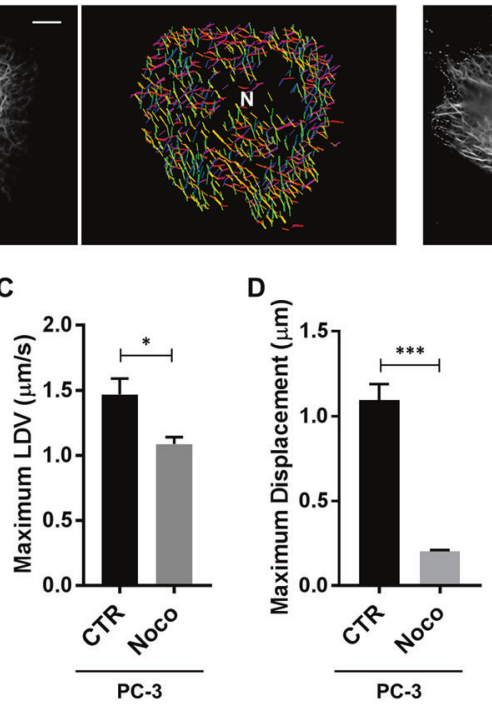

PC-3

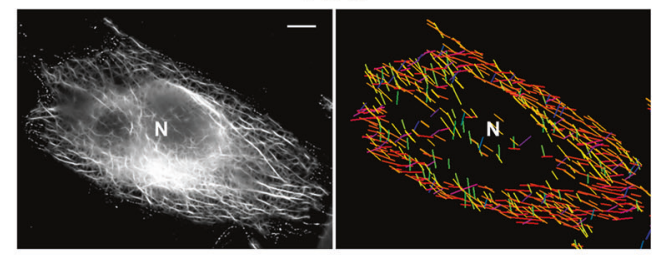

E

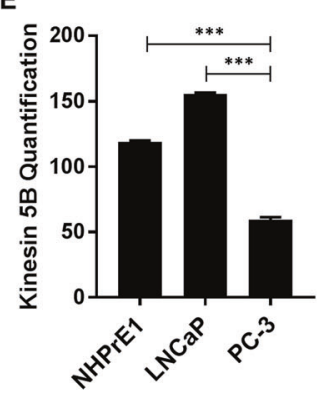

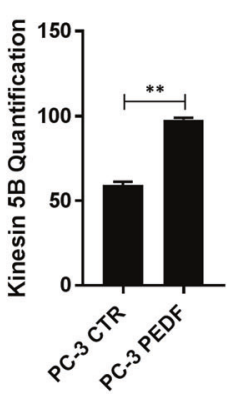

Fig. 5 MT architecture of PCa cells reveals longer MTs with directionality. a In NHPrE1 and PC-3 cells, MTs were stained with $\alpha$-tubulin (black and white channel) and a MT filament analyzer was used to reconstruct the length and directionality (different colors) of the MTs. Scale bars: $10 \mu \mathrm{m}$. b The MT length $(\mu \mathrm{m})$ was measured in aggressive PC-3 cells and compared with NHPrE1 cells. $n=50$. Aggressive PC-3 cells were treated with $5 \mu \mathrm{M}$ Nocodazole (Noco) for

$1.11 \pm 0.11 \mu \mathrm{m} / \mathrm{s} ; P<0.001$ ) (Fig. 5d). Moreover, after the treatment with Nocodazole, directional movement was not observed.

Intracellular LD trafficking via MTs requires molecular motors. In Drosophila embryos, LD motion toward the plusends of MTs is driven by the motor kinesin-1 [51]. More recently, the motor protein kinesin $5 \mathrm{~B}$ (a member of the kinesin-1 family) has been implicated as a regulator of triglyceride content and LD movement in mammals [37]. We tested whether this motor protein was altered in our high velocity cell line compared with normal epithelial cells. Aggressive PC-3 cells expressed significantly lower protein levels when compared with lower aggressive $\mathrm{LNCaP}$ cells (PC-3 vs LNCaP: $59.40 \pm 1.40$ vs $155.90 \pm 0.60 ; P<0.001$ ) and normal epithelial cells (PC-3 vs NHPrE1: $59.40 \pm 1.40$ vs $119.00 \pm 0.75 ; P<0.001$ ) (Fig. 5 e). The treatment with exogenous PEDF increased the protein levels of kinesin 5B in PC-3 cells when compared with the untreated cells (PC-3 PEDF vs PC-3 C: $97.95 \pm 0.85$ vs $59.40 \pm 1.40 ; P<0.01$ ) (Fig. 5f).

\section{Discussion}

The TME is influenced by many extrinsic factors including hypoxia, immune cells, acidity, and metabolites [52-54]. Acidification can play an important role in nutrient sensing and energy-related processes. Plasma membrane
$4 \mathrm{~h}$ and $\mathbf{c}$ LDVmax and $\mathbf{d}$ Dmax were measured and compared with the controls (CTR). (e) Kinesin 5B levels were quantified in NHPrE1, LNCaP, and PC-3 cells after normalization by GAPDH. f Kinesin 5B levels were quantified in PC-3 control (CTR) and PC-3 treated with PEDF after normalization by GAPDH. Values are mean \pm SEM. Student's unpaired t-test. $* P<0.05, \quad * * P<0.01, \quad * * * P<0.001$, $* * * * P<0.0001$

V-ATPases are ATP-dependent proton pumps, which can activate $\mathrm{Wnt} / \beta$-catenin signaling $[2,48,49,55]$ and be amplified in about one-third of breast cancers as well as other tumors $[3,56]$. In the current study, we found an increase in V-ATPase in the more aggressive and higher LDV cell line, PC-3. Active $\beta$-catenin was also increased in the same cell line when compared with the benign cells. In $\mathrm{PCa}$, other studies have shown prostate-specific antigen (PSA) is a common biomarker and blockade of V-ATPase with Bafilomycin A or Concanamycin A reduced PSA mRNA levels and PCa cell invasion [8]. In a more recent study, these same inhibitors also significantly reduced androgen receptor (AR) protein levels in $\mathrm{PCa}$; this study also demonstrated the dependence of AR repression on VATPase [57]. Our data support another role for V-ATPase in regulating LD distribution within the cytoplasm and control of LDV. Under more acidic conditions, the LDs started to form small aggregates and moved from a random distribution cytoplasmic pattern to the peripheral region along the cell membrane. MMP-9 was observed on the surface of these LDs, which brings a key enzyme to facilitate potential invasion. The position of the LD clusters, as a rich nutrient source, has the potential to facilitate energydriven tumorigenic processes such as invasion of the neighboring tissue. Blockade of V-ATPase was also able to slow down the fast moving LDs with directionality in the more aggressive cancer cells to a velocity comparable to one measured in normal epithelial cells. A limited number 
of studies have linked this proton pump to lysosomal trafficking [58] and reorganization of the F-actin cytoskeleton [57]. To our knowledge, this is the first study to support that V-ATPase can regulate intracellular LDV. A proposed model demonstrates how V-ATPase may interact with other molecules to alter LDV (see supplementary data, Fig. S2C).

Lipid dysregulation has been documented in many types of cancer [59, 60]. Maintaining the proper net neutral lipid content in normal cells requires precision in the signaling between lipogenesis and lipolytic enzymes in TAG metabolism. Human tissue samples undergo fixation and processing procedures, which alter lipids, thus, making it more difficult to visualize them under the microscope. In this study, we noticed a higher density of intracellular vacuoles in more advanced GS prostate tumors. Since lipolytic enzyme ATGL resides on the surface of LDs, we stained the formalin-fixed tissue samples for this protein. In addition, we immunolocalized PLIN2 to the intracytoplasmic LDs. This allowed us to observe a stepwise increase in intracellular LDs across tumor grades. The less aggressive GS 6 tumors revealed ATGL immunoreactivity in the cells near the basement membrane and basal cells, whereas the more aggressive GS 9 tumors demonstrated distinctive clusters of LDs within the cytoplasm of tumor cells. GS 9 tumors in tissue sections also revealed the highest LD cross-sectional area when compared with low-grade tumors and normal prostate epithelial cells. Interesting, the PC-3 cell line revealed smaller LDs that could influence velocity. A study of ex vivo helium droplets revealed smaller sized droplets were capable of moving faster [61]. Both lipogenesis and lipolysis enzymes, DGAT1 and ATGL, as well as a hydrolase, ABHD5, have been reported to be overexpressed in PCa cells [62], and the higher level of ABHD5 appears to act as an inhibitor of PCa growth and invasion [63]. PEDF is made by nearly all normal cells and the expression of this protein is significantly reduced in most tumor cell types [21]. The consequence of PEDF loss can be multifunctional since it has a broad range of antitumor activities [21, 40,50] and its pro-lipolytic role as a binding partner of ATGL alters intracellular neutral lipid in several cell types $[19,20,64,65]$. In addition, PEDF has been shown to reduce the function of V-ATPase in castration-refractory PCa cells [6]. In the current study, we found a new bioactivity for PEDF in lipid trafficking related to its ability to decrease the velocity of intracellular LDs especially in more aggressive cancer cells. Unlike normal cells, many cancer cells have minimal expression of PEDF, thus, it is possible that the elevated $\mathrm{LD}$ velocities observed in the more aggressive cell lines are due, in part, to the loss of an inhibitory role of PEDF, directly or indirectly, on LD movement. Restoration of PEDF in the more aggressive PC3 cells resulted in a significant increase in Kinesin $5 \mathrm{~B}$ protein levels; however, in Drosophila, an increase in kinesin-1 levels was not associated with elevated LDs velocities or a change in travel distance [51, 66]. A more recent model system supported the possibility of detachment of motor protein, kinesin-1, during "traffic jam" situations [67], while another study discovered kinesin in hepatocytes controls both triglyceride secretion as well as LD transport [37]. Additional studies are required to better understand the relationship between LDV and motor proteins in tumor cells and whether one function of kinesin in cancer metabolism is related to triglyceride secretion.

In this study, we investigated whether LDV and displacement correlate with a more aggressive cancer cell phenotype by testing a spectrum of cancer cell lines (prostate, breast, and pancreatic) derived from lowaggressive tumors and higher aggressive or metastatic tumors. We used BODIPY staining for all experimental groups [68]. We found a consistent pattern whereby the aggressive cell lines exhibited significantly higher LDV (LDVmax) and displacement (Dmax) than the lowaggressive or normal epithelial cells. Surprisingly, the most aggressive cells from all three different cell types had similar values for LDVmax suggesting the possibility that acceleration of LDV has an upper threshold in cancer cells, perhaps limited by the availability of functional molecular motor proteins or the complexity of the MT network. LDs utilize MTs to facilitate transport of cargo proteins within the cytoplasmic compartment [69] and we observed that more aggressive cells had directionality and often formed doublets. To determine whether the longer distance and directional movement of LDs was a potential consequence of morphology of the MTs, we studied the distribution of MTs using special imaging programs. We found that the complexity of the MT network was higher in the aggressive PCa cells compared with normal epithelial cells. The MT length was longer and there was the presence of "intersections", which have been recognized to influence cargo transportation patterns [70]. In summary, this study identifies new bioactivities for V-ATPase and PEDF as modulators of LDV. Given the consistency of higher LDV across various aggressive or metastatic cancer cell lines, additional testing of LDV in primary and metastatic cancer cells could prove to be beneficial in understanding the signaling mechanisms for accelerated LD trafficking in the TME.

Acknowledgements We would like to thank Drs Chuhan Chung and Carole Vogler for helpful discussions, Dr Jane McHowat for sharing cell lines, and Dr Lijun Huang, Mona Cornwell, and Shannon Kispert for technical assistance.

\section{Compliance with ethical standards}

Conflict of interest The authors declare that they have no conflict of interest. 
Publisher's note: Springer Nature remains neutral with regard to jurisdictional claims in published maps and institutional affiliations.

\section{References}

1. Gillies RJ, Gatenby RA. Hypoxia and adaptive landscapes in the evolution of carcinogenesis. Cancer Metastasis Rev. 2007;26:311-7.

2. Collins MP, Forgac M. Regulation of V-ATPase assembly in nutrient sensing and function of V-ATPases in breast cancer metastasis. Front Physiol. 2018;9:902.

3. Whitton B, Okamoto H, Packham G, Crabb SJ. Vacuolar ATPase as a potential therapeutic target and mediator of treatment resistance in cancer. Cancer Med. 2018;7:3800-11.

4. Chung C, Mader CC, Schmitz JC, Atladottir J, Fitchev P, Cornwell ML, et al. The vacuolar-ATPase modulates matrix metalloproteinase isoforms in human pancreatic cancer. Lab Invest. 2011;91:732-43.

5. Hinton A, Sennoune SR, Bond S, Fang M, Reuveni M, Sahagian $\mathrm{GG}$, et al. Function of a subunit isoforms of the V-ATPase in $\mathrm{pH}$ homeostasis and in vitro invasion of MDA-MB231 human breast cancer cells. J Biol Chem. 2009;284:16400-8.

6. Sennoune SR, Bermudez LE, Lees JC, Hirsch J, Filleur S, Martinez-Zaguilan R. Vacuolar H+-ATPase is down-regulated by the angiogenesis-inhibitory pigment epithelium-derived factor in metastatic prostate cancer cells. Cell Mol Biol (Noisy-le-grand). 2014;60:45-52.

7. Xu X, You J, Pei F. Silencing of a novel tumor metastasis suppressor gene LASS2/TMSG1 promotes invasion of prostate cancer cell in vitro through increase of vacuolar ATPase activity. J Cell Biochem. 2012;113:2356-63.

8. Michel V, Licon-Munoz Y, Trujillo K, Bisoffi M, Parra KJ. Inhibitors of vacuolar ATPase proton pumps inhibit human prostate cancer cell invasion and prostate-specific antigen expression and secretion. Int J Cancer. 2013;132:E1-10.

9. Perez-Sayans M, Somoza-Martin JM, Barros-Angueira F, Rey JM, Garcia-Garcia A. V-ATPase inhibitors and implication in cancer treatment. Cancer Treat Rev. 2009;35:707-13.

10. Abramczyk H, Surmacki J, Kopec M, Olejnik AK, LubeckaPietruszewska K, Fabianowska-Majewska K. The role of lipid droplets and adipocytes in cancer. Raman imaging of cell cultures: MCF10A, MCF7, and MDA-MB-231 compared to adipocytes in cancerous human breast tissue. Analyst. 2015;140:2224-35.

11. Qi W, Fitchev PS, Cornwell ML, Greenberg J, Cabe M, Weber CR, et al. FOXO3 growth inhibition of colonic cells is dependent on intraepithelial lipid droplet density. J Biol Chem. 2013;288:16274-81.

12. Tirinato L, Liberale C, Di Franco S, Candeloro P, Benfante A, La Rocca R, et al. Lipid droplets: a new player in colorectal cancer stem cells unveiled by spectroscopic imaging. Stem Cells. 2015;33:35-44.

13. Bartel K, Winzi M, Ulrich M, Koeberle A, Menche D, Werz O, et al. V-ATPase inhibition increases cancer cell stiffness and blocks membrane related Ras signaling - a new option for HCC therapy. Oncotarget. 2017;8:9476-87.

14. Costa GA, de Souza SB, da Silva Teixeira LR, Okorokov LA, Arnholdt ACV, Okorokova-Facanha AL, et al. Tumor cell cholesterol depletion and V-ATPase inhibition as an inhibitory mechanism to prevent cell migration and invasiveness in melanoma. Biochim Biophys Acta. 2018;1862:684-91.

15. Daemen S, van Zandvoort M, Parekh SH, Hesselink MKC. Microscopy tools for the investigation of intracellular lipid storage and dynamics. Mol Metab. 2016;5:153-63.

16. Fujimoto T, Parton RG. Not just fat: the structure and function of the lipid droplet. Cold Spring Harb Perspect Biol. 2011;3:1-17.
17. Khor VK, Shen WJ, Kraemer FB. Lipid droplet metabolism. Curr Opin Clin Nutr Metab Care. 2013;16:632-7.

18. Walther TC, Farese RV Jr. Lipid droplets and cellular lipid metabolism. Annu Rev Biochem. 2012;81:687-714.

19. Borg ML, Andrews ZB, Duh EJ, Zechner R, Meikle PJ, Watt MJ. Pigment epithelium-derived factor regulates lipid metabolism via adipose triglyceride lipase. Diabetes. 2011;60:1458-66.

20. Zhang H, Sun T, Jiang X, Yu H, Wang M, Wei T, et al. PEDF and PEDF-derived peptide $44 \mathrm{mer}$ stimulate cardiac triglyceride degradation via ATGL. J Transl Med. 2015;13:68.

21. Becerra SP, Notario V. The effects of PEDF on cancer biology: mechanisms of action and therapeutic potential. Nat Rev Cancer. 2013;13:258-71.

22. Crawford SE, Stellmach V, Ranalli M, Huang X, Huang L, Volpert O, et al. Pigment epithelium-derived factor (PEDF) in neuroblastoma: a multifunctional mediator of Schwann cell antitumor activity. J Cell Sci. 2001;114(Pt 24):4421-8.

23. Filleur S, Nelius T, de Riese W, Kennedy RC. Characterization of PEDF: a multi-functional serpin family protein. J Cell Biochem. 2009;106:769-75.

24. Belkacemi L, Atkins JL, Yang LU, Gadgil P, Sater AK, Chow DS. et al. Phosphaplatin anti-tumor effect enhanced by liposomes partly via an up-regulation of PEDF in breast cancer. Anticancer Res. 2018;38:623-46.

25. Halin S, Rudolfsson SH, Doll JA, Crawford SE, Wikstrom P, Bergh A. Pigment epithelium-derived factor stimulates tumor macrophage recruitment and is downregulated by the prostate tumor microenvironment. Neoplasia. 2010;12:336-45.

26. Harries RL, Owen S, Ruge F, Morgan M, Li J, Zhang Z, et al. Impact of pigment epithelium-derived factor on colorectal cancer in vitro and in vivo. Oncotarget. 2018;9:19192-202.

27. Barbosa AD, Savage DB, Siniossoglou S. Lipid droplet-organelle interactions: emerging roles in lipid metabolism. Curr Opin Cell Biol. 2015;35:91-7.

28. Beller M, Thiel K, Thul PJ, Jackle H. Lipid droplets: a dynamic organelle moves into focus. FEBS Lett. 2010;584:2176-82.

29. Suzuki M, Shinohara Y, Ohsaki Y, Fujimoto T. Lipid droplets: size matters. J Electron Microsc (Tokyo). 2011;60(Suppl 1): S101-16.

30. Valm AM, Cohen S, Legant WR, Melunis J, Hershberg U, Wait E, et al. Applying systems-level spectral imaging and analysis to reveal the organelle interactome. Nature. 2017;546:162-7.

31. Herms A, Bosch M, Reddy BJ, Schieber NL, Fajardo A, Ruperez $\mathrm{C}$, et al. AMPK activation promotes lipid droplet dispersion on detyrosinated microtubules to increase mitochondrial fatty acid oxidation. Nat Commun. 2015;6:7176.

32. Welte MA. Fat on the move: intracellular motion of lipid droplets. Biochem Soc Trans. 2009;37(Pt 5):991-6.

33. Orlicky DJ, Monks J, Stefanski AL, McManaman JL. Dynamics and molecular determinants of cytoplasmic lipid droplet clustering and dispersion. PLoS ONE. 2013;8:e66837.

34. Brasaemle DL, Dolios G, Shapiro L, Wang R. Proteomic analysis of proteins associated with lipid droplets of basal and lipolytically stimulated 3T3-L1 adipocytes. J Biol Chem. 2004;279:46835-42.

35. Guo Y, Walther TC, Rao M, Stuurman N, Goshima G, Terayama $\mathrm{K}$, et al. Functional genomic screen reveals genes involved in lipid-droplet formation and utilization. Nature. 2008;453:657-61.

36. Welte MA, Gould AP. Lipid droplet functions beyond energy storage. Biochim Biophys Acta. 2017;1862(10 Pt B):1260-72.

37. Rai P, Kumar M, Sharma G, Barak P, Das S, Kamat SS, et al. Kinesin-dependent mechanism for controlling triglyceride secretion from the liver. Proc Natl Acad Sci USA. 2017; 114:12958-63. 
38. Parker AL, Kavallaris M, McCarroll JA. Microtubules and their role in cellular stress in cancer. Front Oncol. 2014;4:153.

39. Dawson DW, Volpert OV, Gillis P, Crawford SE, Xu H, Benedict W, et al. Pigment epithelium-derived factor: a potent inhibitor of angiogenesis. Science. 1999;285:245-8.

40. Doll JA, Stellmach VM, Bouck NP, Bergh AR, Lee C, Abramson LP, et al. Pigment epithelium-derived factor regulates the vasculature and mass of the prostate and pancreas. Nat Med. 2003;9:774-80.

41. Gorelik R, Gautreau A. Quantitative and unbiased analysis of directional persistence in cell migration. Nat Protoc. 2014;9: 1931-43.

42. Eltzner B, Wollnik C, Gottschlich C, Huckemann S, Rehfeldt F. The filament sensor for near real-time detection of cytoskeletal fiber structures. PLoS One. 2015;10:e126346.

43. Suzuki M, Murakami T, Cheng J, Kano H, Fukata M, Fujimoto T. ELMOD2 is anchored to lipid droplets by palmitoylation and regulates adipocyte triglyceride lipase recruitment. Mol Biol Cell. 2015;26:2333-42.

44. Cai J, Parr C, Watkins G, Jiang WG, Boulton M. Decreased pigment epithelium-derived factor expression in human breast cancer progression. Clin Cancer Res. 2006;12(11 Pt 1):3510-7.

45. Halin S, Wikstrom P, Rudolfsson SH, Stattin P, Doll JA, Crawford SE, et al. Decreased pigment epithelium-derived factor is associated with metastatic phenotype in human and rat prostate tumors. Cancer Res. 2004;64:5664-71.

46. Uehara H, Miyamoto M, Kato K, Ebihara Y, Kaneko H, Hashimoto $\mathrm{H}$, et al. Expression of pigment epithelium-derived factor decreases liver metastasis and correlates with favorable prognosis for patients with ductal pancreatic adenocarcinoma. Cancer Res. 2004;64:3533-7.

47. Kolosenko I, Avnet S, Baldini N, Viklund J, De Milito A. Therapeutic implications of tumor interstitial acidification. Semin Cancer Biol. 2017;43:119-33.

48. Pamarthy S, Kulshrestha A, Katara GK, Beaman KD. The curious case of vacuolar ATPase: regulation of signaling pathways. Mol Cancer. 2018;17:41.

49. Jung YS, Jun S, Kim MJ, Lee SH, Suh HN, Lien EM, et al. TMEM9 promotes intestinal tumorigenesis through vacuolarATPase-activated Wnt/beta-catenin signalling. Nat Cell Biol. 2018;20:1421-33.

50. Nardi F, Fitchev P, Franco OE, Ivanisevic J, Scheibler A, Hayward SW, et al. PEDF regulates plasticity of a novel lipidMTOC axis in prostate cancer-associated fibroblasts. J Cell Sci. 2018;131:1-15.

51. Shubeita GT, Tran SL, Xu J, Vershinin M, Cermelli S, Cotton SL, et al. Consequences of motor copy number on the intracellular transport of kinesin-1-driven lipid droplets. Cell. 2008;135:1098-107.

52. Lyssiotis CA, Kimmelman AC. Metabolic interactions in the tumor microenvironment. Trends Cell Biol. 2017;27:863-75.

53. Samanta D, Semenza GL. Metabolic adaptation of cancer and immune cells mediated by hypoxia-inducible factors. Biochim Biophys Acta. 2018;1870:15-22.
54. Schito L. Bridging angiogenesis and immune evasion in the hypoxic tumor microenvironment. Am J Physiol Regul Integr Comp Physiol. 2018;315:R1072-84.

55. Toei M, Saum R, Forgac M. Regulation and isoform function of the V-ATPases. Biochemistry. 2010;49:4715-23.

56. McConnell M, Feng S, Chen W, Zhu G, Shen D, Ponnazhagan $\mathrm{S}$, et al. Osteoclast proton pump regulator Atp6v1c1 enhances breast cancer growth by activating the mTORC1 pathway and bone metastasis by increasing V-ATPase activity. Oncotarget. 2017;8:47675-90.

57. Licon-Munoz Y, Michel V, Fordyce CA, Parra KJ. F-actin reorganization by V-ATPase inhibition in prostate cancer. Biol Open. 2017;6:1734-44.

58. Meo-Evoli N, Almacellas E, Massucci FA, Gentilella A, Ambrosio S, Kozma SC, et al. V-ATPase: a master effector of E2F1-mediated lysosomal trafficking, mTORC1 activation and autophagy. Oncotarget. 2015;6:28057-70.

59. Shyu P Jr, Wong XFA, Crasta K, Thibault G dropping in on lipid droplets: insights into cellular stress and cancer. Biosci Rep. 2018;38:1-20.

60. Martinez-Outschoorn UE, Peiris-Pages M, Pestell RG, Sotgia F, Lisanti MP. Cancer metabolism: a therapeutic perspective. Nat Rev Clin Oncol. 2017;14:11-31.

61. Alghamdi M, Zhang J, Oswalt A, Porter JJ, Mehl RA, Kong W. Doping of green fluorescent protein into superfluid helium droplets: size and velocity of doped droplets. J Phys Chem A. 2017;121:6671-8.

62. Mitra R, Le TT, Gorjala P, Goodman OB Jr. Positive regulation of prostate cancer cell growth by lipid droplet forming and processing enzymes DGAT1 and ABHD5. BMC Cancer. 2017;17:631.

63. Chen G, Zhou G, Aras S, He Z, Lucas S, Podgorski I, et al. Loss of ABHD5 promotes the aggressiveness of prostate cancer cells. Sci Rep. 2017;7:13021.

64. Notari L, Baladron V, Aroca-Aguilar JD, Balko N, Heredia R, Meyer $\mathrm{C}$, et al. Identification of a lipase-linked cell membrane receptor for pigment epithelium-derived factor. J Biol Chem. 2006;281:38022-37.

65. Chung C, Doll JA, Gattu AK, Shugrue C, Cornwell M, Fitchev P, et al. Anti-angiogenic pigment epithelium-derived factor regulates hepatocyte triglyceride content through adipose triglyceride lipase (ATGL). J Hepatol. 2008;48:471-8.

66. Welte MA, Gross SP, Postner M, Block SM, Wieschaus EF. Developmental regulation of vesicle transport in Drosophila embryos: forces and kinetics. Cell. 1998;92:547-57.

67. Rank M, Frey E. Crowding and pausing strongly affect dynamics of Kinesin-1 motors along microtubules. Biophys J. 2018;115:1068-81.

68. Paar M, Jungst C, Steiner NA, Magnes C, Sinner F, Kolb D, et al. Remodeling of lipid droplets during lipolysis and growth in adipocytes. J Biol Chem. 2012;287:11164-73.

69. Welte MA. As the fat flies: the dynamic lipid droplets of Drosophila embryos. Biochim Biophys Acta. 2015;1851:1156-85.

70. Bergman JP, Bovyn MJ, Doval FF, Sharma A, Gudheti MV, Gross SP, et al. Cargo navigation across 3D microtubule intersections. Proc Natl Acad Sci USA. 2018;115:537-42. 